\title{
El divorcio en el Cádiz del siglo XVIII (1)
}

\begin{abstract}
ARTURO MORGADO GARCIA
Durante el Antiguo Régimen el matrimonio, bien como sacramento, bien como contrato meramente civil, se caracteriza por su carácter indisoluble. Incluso en un país protestante, cual Inglaterra, el divorcio únicamente es posible en ocasiones sumamente excepcionales, y los costosos trámites que implicaba su consecución provocaron que, en la práctica, solamente estuviera al alcance de la alta nobleza: tan sólo 115 fueron concedidos en la segunda mitad del siglo XVIII (2).

Más restrictiva se muestra la Iglesia católica, en la cual el divorcio quod thorum et habitationem no conllevaba la disolución del vínculo matrimonial, limitándose a permitir la separación de los cónyuges. Las causas que motivan su concesión han variado muy poco a lo largo de los siglos (3), y las mismas se reducen a adulterio (la única que provoca una separación perpetua, equiparándose al mismo la sodomía y la bestialidad), el ingreso en una secta acatólica, la impartición de una educación no católica a los hijos por parte de alguno de.los cónyuges, el llevar una vida ignominiosa desde el punto de vista moral, el causar graves peligros para el alma o el cuerpo del cónyuge y la comisión de sevicias o malos tratos, tanto físicos como espirituales (insultos, injurias, calumnias, amenazas de muerte), si bien todas estas situaciones solamente permiten obtener una separación temporal, que persiste en tanto no den término las circunstancias que han provocado la misma: El juez competente es el obispo, y por delegación de éste el Vicario General, aunque sus sentencias son apelables ante el Tribunal Metropolitano y ante la Rota.

Aún más difícil es la anulación del matrimonio, siendo las únicas causas que pueden provocar la misma la existencia de impedimentos espirituales o de parentesco entre los contrayentes, el haber sido forzado al mismo, y la impotencia (que no la esterilidad) de uno de los cónyuges (4), siendo juez competente en esta
\end{abstract}

(1) Una primera versión de este trabajo fue dada a cotiocer en el II Coloquio de Historias Locales celebrado en Cádiz en 1990 con el título "Demandas y divorcios en el Cádiz del siglo XVIII", cuyas actas aún se encuentran pendientes de publicación. De cara a la rédacción de este artículo nos hemos centrado única y exclusivamente en el fenómeno divorcista, modificando en profundidad los planteamientos originales y el aparató crítico empleado.

(2) BURGUIERE, A., et al., Historia de la familia, vol: 2, Madrid, Alianza, 1988.

(3) Vid. BERNARDEZ CANTON, A., Las causas canónicas de separación conyugal, Madrid, 1961.

(4) Según Darmon, desde el 'siglo XVI este factor es el causante de la mayor parte de las anulaciones (DARMON, P., Le tribunal de l' impuissance. Virilité et defaillances conjugales dans l' Ancienne France, París, Du Seuil, 1986).

DOI: http://dx.doi.org/10.25267/Trocadero.1995.i6.07 
materia la Santa Sede y no los ordinarios, que solamente pueden llevar a cabo los trámites preliminares del procedimiento canónico, pero no dictar sentencia.

\section{UN RECURSO LIMITADO}

Dado las reticencias de las autoridades eclesiásticas a la concesión del divorcio, su presencia es bastante limitada. Para el Cádiz dieciochesco se conservan tan sólo un total de 380 solicitudes de separación o nulidad matrimonial (5), si bien nosotros hemos operado sobre una muestra de 289 pleitos (6). La cronología de los mismos es muy irregular (7), por lo que no podemos establecer conclusiones fiables en este sentido, pero todo parece indicar que el fenómeno divorcista tuvo una incidencia muy pequeña: tal como bien muestra Pérez Serrano la tasa de divorcialidad (relación entre matrimonios celebrados y solicitudes de divorcio) ascendería al 0,06 por mil durante las tres últimas décadas de la centuria (8), lo cual, en palabras del autor, suponen proporciones completamente irreales. Siempre es posible achacar tan reducidas tasas a lagunas existentes en la documentación, pero en otras regiones españolas se ha constatado también la excepcionalidad de este arbitrio: en la diócesis de Barcelona García Cárcel, por ejemplo, solamente contabilizó 152 pleitos entre 1565 y 1650 (9).

Sería una ingenuidad por nuestra parte pretender que los matrimonios infelices fueron una ínfima minoría en el Cádiz dieciochesco, por lo que las explicaciones habrá que buscarla en otros factores: el divorcio es un recurso caro desde el punto de vista económico, y tan sólo una pequeña minoría de la población gaditana estaba en disposición de afrontar el elevado costo del proceso legal que el mismo requería. Un botón de muestra: los gastos derivados de la separación conyugal de Pedro Yuglar y María Milla se elevaron en 1794 a la suma de 172 pesos (10).

Pero es que, además, la situación de malestar conyugal quedaba públicamente expuesta a toda la comunidad (en 1705 una demandante aludía a la nota que causaría en esta ciudad) (11), a veces durante mucho tiempo, por cuanto alguno de estos pleitos se prolongó incluso durante años (y pensemos lo que ello podía suponer de descrédito social para ciertos sectores de la población gaditana); por lo que es más que probable que los cónyuges insatisfechos decidiesen solucionar sus problemas de convivencia por sus propios medios (alternativa, por

(5) ADC, Varios, leg. 102, 154, 185, 267, 271, 277, 305, 337, 345, 346, 395, 495, 529, 568, $623-629,631-633,640,643,644,669,675,676,680,683-686,688,690,701,704,705,707$, $708,729,731,733,739,742,743,750,783,802,805,903,935,1049,1050,1054-1056,1064$, 1139, 1163, 1198. A la hora de referimos a un expediente concreto lo citamos por el legajo, nombre del demandante y año.

(6) ADC, Varios, leg. 102-743, 802, 805, 1163.

(7) 17 en $1700-09,281710-19,51720-29,341730-39,61740-49,361750-59,271760-69,32$ $1770-79,651780-89,391790-99$.

(8) PEREZ SERRANO, J., Cádiz la ciudad desnuda. Cambio económico y modelo demográfico en la formación de la Andalucía contemporänea, Cádiz, Universidad, 1992, p. 215.

(9) GARCIA CARCEL, R., Historia de Cataluña, vol. 1, Barcelona, Ariel, 1985.

(10) ADC, Varios, leg. 1164, María Milla (1794).

(11) 337, Francisca Serrano, (1717). 
supuesto, siempre rechazada por las autoridades eclesiásticas) (12) u optasen por el abandono puro y simple de su pareja (13) antes que acudir a los tribunales eclesiásticos para dirimir sus diferencias conyugales.

En la mayor parte de los casos la solicitud de divorcio es iniciada por la esposa (predominio femenino constatado igualmente en Cataluña y en Extremadura) (14), y solamente en 48 ocasiones es el varón quien toma la decisión de separarse. Esta situación no resulta en absoluto extraña: tengamos en cuenta, en primer lugar, la situación de inferioridad legal, jurídica y social padecida por la mujer a lo largo del Antiguo Régimen y que la convierte en la parte más vulnerable del matrimonio. $\mathrm{Y}$, no menos importante, en un modelo familiar sumamente patriarcal cual es el que se da en el período objeto de nuestro estudio, todo varón que pretendiera dar este paso podía exponerse a la burla y a la irrisión por parte de sus convecinos por cuanto bien podía dar la impresión de una neta incapacidad para el buen gobierno de su casa.

Parece bastante llamativo que, en contra de lo que cabría esperar, sean las capas bajas y medias de la población las que más acudan a los tribunales eclesiásticos para resolver sus problemas conyugales (15), lo que resulta paradójico si, como parece evidente, en muchos casos su débil capacidad económica no les permitiría acometer los gastos del proceso, pero es preciso tener en cuenta que en los estratos más privilegiados de la sociedad gaditana el uso de este arbitrio se vería frenado por el escándalo social al que los cónyuges deberían hacer frente, ya que era sencillamente imposible mantener el desarrollo del proceso de una forma discreta, por cuanto era frecuente el interrogatorio de testigos presenciales, y, a veces, incluso de los propios familiares. Tal como bien señala García Cárcel para el caso barcelonés, sólo se separa el que tiene muy poco que perder (16): bien porque no tenga que arrastrar la pesada carga del honor, bien porque la convivencia mutua resulta sencillamente imposible.

No es demasiado común que los pleitos se inicien inmediatamente después de haber tenido lugar el enlace matrimonial, lo que nos muestra que el divorcio

(12) En 1726 el Fiscal General Eclesiástico denunciaba cómo Diego Chriselon y Antonia Graner habían separado de mutuo acuerdo sus personas y sus bienes, de lo que se seguía "a el matrimonio y prole grave perjuicio e injuria y notable escándalo" (MORGADO GARCIA, A., Iglesia y sociedad en el Cádiz del siglo XVIII, Cádiz, 1989, pp. 197-198).

(13) De hecho, la interpretación que los últimos estudios dan a los casos de bigamia que aparecen en la documentación inquisitorial, apunta siempre a señalar cómo se trata en la mayoría de los casos de cónyuges insatisfechos que deciden abandonar a su cónyuge e iniciar una nueva vida. Vid. TESTON NUÑEZ, I., Amor, sexo y matrimonio en Extremadura, Badajoz, 1985; CONTRERAS, J., El Santo Oficio de la Inquisición en Galicia, Madrid, 1982; GARCIA $C A R C E L, R$., Herejía y sociedad en el siglo XVT. La Inquisición en Valencia, Barcelona, 1980.

(14) TESTON NUÑEZ, I., op. cit., GARCIA CARCEL, R., Historia...

(15) El elenco socioprofesional conocido es el siguiente: un regidor, cuatro comerciantes, un hombre de negocios, un corredor de lonja, un dueño de tienda de mondas, un impresor, un abogado, dos cirujanos, un médico, un oficial de la Casa de Contratación, un dependiente de rentas reales, un capataz de la fábrica de tabaco, un ayo de Gramática, un dependiente, un empleado en pescadería, seis carpinteros, cuatro zapateros, dos pintores, cinco peluqueros; dos albañiles, un ropero, tres marineros, tres sastres, un mandadero, un calafate, un dorador, un batero, un ayudante real, un gitano, un pardo y dos negros.

(16) GARCIA CARCEL, R., Historia. 
responde más a una lenta degradación de la convivencia cotidiana a que ésta desde el principio haya tomado un sesgo brutal. En 64 ocasiones el divorcio se pide tras haber transcurrido menos de cinco años de haberse contraído el matrimonio, en 42 de 5 a 9 años, en 38 de 10 a 15 años, en 18 de 15 a 19 años, en 10 más de 20 años, siendo interesante reseñar cómo en ciertas ocasiones la parte denunciante manifiesta haber sobrellevado una situación injuriosa durante muchos años con paciencia y resignación, viéndose abocada a solicitar la separación ante la nula disposición de su cónyuge a cambiar de actitud: el abogado de Juana Revello, solicitante del divorcio a los 21 años de matrimonio, expresaba cómo su marido desde el principio "dio a entender su mal genio y temible condición no obstante dicha mi parte lo fue sobrellevando con amor y cariño" (17).

Las motivaciones alegadas por los demandantes no son demasiado originales, al menos por lo que se ha constatado en el Cádiz del XIX, la Extremadura del Antiguo Régimen, la Cataluña del siglo XVI o la Francia de finales del XVIII (18), existiendo un gran dimorfismo sexual al respecto.

\section{LA INDEFENSION DE LAS ESPOSAS}

Sin lugar a dudas, los malos tratos constituyen el motivo principal de divorcio: en 169 ocasiones aparecen las agresiones físicas (el 70,1\% de las demandas femeninas) que se suelen manifestar en golpes y heridas con arma blanca, a veces propinados con suma brutalidad: "le echó encima una sarteneja de lumbre con que le abrasó los pechos y la cara y en otra ocasión le dio un golpe asimismo en la cara con que le hirió gravemente siendo preciso darle algunos puntos...y en otras muchas ocasiones la corrió con el espadín para quererla matar" (19), "llegó a ponerle una pistola a los pechos" (20), "hacerle saltar la sangre con bofetadas y porrazos por boca y narices" (21), "estando embarazada la arrastró por los cabellos en una calle publica y en otra la ha perseguido con un cuchillo" (22). Ultrajes que en ocasiones se producen en presencia de los vecinos, que se ponen a favor de la parte más débil y acuden pronto al auxilio de la víctima (23), evitando muchas veces males mayores.

La actitud de las mujeres ante tales tropelías parece ambigua: es cierto que las esposas ultrajadas manifiestan en todos los casos un profundo rechazo a estos abusos de autoridad (una demandante, Margarita Pomette, llegó a decir que su marido la trataba "como si fuera su esclava") (24), pero no protestan tanto por la

(17) 683, Juana Revello (1757).

(18) GARCIA CARCEL, R., Historia; TESTON NUÑEZ, I., op. cit.; RAMOS SANTANA, A., La burguesia gaditana en la época isabelina, Cádiz, 1987; PHILLIPS, R.G., "Le divorce en France á la fin du XVIIle siécle", Annales E.S.C., XXXIV, 2, 1979.

(19) 154, Bernarda Jacinta de Salvatierra (1715).

(20) 395, Vicenta Pérez (1756).

(21) 395, María Palomino (1756).

(22) 568, María Albenoi (1778).

(23) Los comportamientos en muchos casos son coincidentes: está solidaridad vecinal a favor de la víctima ha sido constatada asimismo en el París dieciochesco (FARGE, A., La vie fragile. Violence, pouvoirs el solidarités à Paris au XVIIle siécle, París, Hachette, 1986).

(24) 346, Margarita Pomette (1704). 
brutalidad del cónyuge sino porque la misma es injustificada al haber cumplido escrupulosamente con sus obligaciones: "he procurado vivir vida maridable con el susodicho sin darle ocasión de enojo" (25), "viviendo honesta y recogidamente cuidando de su persona.y de sus dos hijos que trajo al dicho matrimonio y sin darle motivo" (26), "se ha esmerado en cuidar, estimar y obsequiar al prenotado su marido con el mayor desvelo y todo el cariño indispensable" (27), "se ha portado con notoria honradez asistiéndolo y cuidándolo en un todo y cumpliendo con las obligaciones de su estado" (28), afirmaciones en las que, por otra parte, no hacen más que reflejar el modelo de esposa cristiana defendido por los moralistas católicos (29).

En suma: la protesta no viene ocasionada tanto por los malos tratos sino porque éstos se produzcan sin motivo. Ello nos revela hasta qué punto había penetrado en las mentes un argumento tan repetido por los moralistas y los canonistas de la época cual es el derecho de corrección del esposo a los restantes miembros de la familia cuando éstos manifiestan una actitud de rebeldía ante su autoridad: un autor como Arbiol en "La familia regulada con doctrina de la Sagrada Escritura y Santos Padres de la Iglesia Católica" (4ª edición, Barcelona, 1769), manifiesta que el marido tiene derecho a "una corrección caritativa y algún moderado castigo" (30), y estos argumentos son repetidos en ciertas ocasiones por los maridos o sus representantes legales. El abogado de Julián Godino justificaba "las reprensiones del marido y aun el castigo prudente a la mujer pues en algunas ocasiones suele ser preciso y saludable segun se explican los autores y que solo lo es la sevicia 'o crueldad" (31). Otros, por su parte, presentarán argumentos similares: "no proporcionarse los genios ni a temperarse la dicha mi mujer a ceder de su ánima entereza en los lances que se ofrecían queriendo muchas veces que observase su gusto" (32), "han motivado las discordias...el genio voluntarioso altivo e intrépido de ésta tratando con desabrimiento y menosprecio a dicha mi parte no queriendo subyugarse a sus racionales preceptos" (33), "aquella sevicia que no sólo no se estima por motivo justo a la separación de un matrimonio sino que se encarga como salutífera para conservación de la buena armonia de él cuando la cónyuge se extravía o desordena y no cede a las racionales amonestaciones de su marido" (34). Si unimos al respaldo doctrinal que estos comportamientos encon-

(25) 346 , Josepha de la Libre (1707).

(26) 611, Catalina María Bermúdez (1733).

(27) 705, Josepha Ganet (1758).

(28) 627, Isabel Ximénez Delgado (1773).

(29) Vid. BARBAZZA, M.C., "L' epouse chrétienne et les moralistes espagnols des XVIe et XVIIe siécles", Melanges de la Casa de Velázquez, XXIV, 1988; RICART SAMPIETRO, D., "El model femení a la Catalunya del XVIII a través de les fonts eclésiastiques", Actes del Primer Congrës d' Historia Moderna de Catalunya, vol. 2, Barcelona, 1984; NOVI CHAVARRIA, E., "Ideologie e comportamenti familiari nei predicatori italiani tra Cinque e Seicento. Tematiche e modelli", Rivista Storica Italiana, 1988.

(30) RICART SAMPIETRO, D., op. cit., p. 635.

(31) 568, Isabel de Soria (1780).

(32) 644, Josepha Monsalbe (1736).

(33) 627, Isabel Ximénez Delgado (1773).

(34) 568, Teresa Quevedo (1780) 
traban, la agresividad latente de continuo en las clases populares gaditanas (35), nos encontraremos con un caldo de cultivo apropiado para la comisión de estos excesos.

Las injurias e insultos aparecen en 101 ocasiones, siendo los más corrientes los de "puta" y "arrastrada", lo que revela una gran obsesión por los aspectos sexuales (36), trascendiendo en ocasiones su formulación el ámbito de lo privado para reforzar el desprecio que en muchas ocasiones el marido sentía hacia su esposa: una demandante declaraba al respecto cómo "el nombre de que frecuentemente usa es llamarme mujer mundana aunque con voz mas escandalosa y que soy la mayor y más desollada que hay en el mundo... a un hijo que tenemos de cuatro años le pregunta cómo me llamo y si responde con mi propio nombre le reprende y le instruye en que me ultraje con las voces que quedan referidas... suele no pocas veces traer amigos a su casa delante de los cuales no solo repite las mismas palabras mencionadas sino que trasciende a darles individuales señas de mi cuerpo" (37). Estas palabras vejatorias, empero, casi nunca aparecen por sí solas, y suelen estar asociadas a malos tratos físicos.

Otras veces se aprecia una cierta crueldad psicológica por parte del varón, manifestada en unos celos desmesurados, encerrar a la mujer en una habitación "sin dejarme comunicación, silla, estrado ni almohada en que sentarme ni menos cama en que dormir escaseando el alimento" (38), echarla de casa sin motivo justificado, etc.

Las esposas también alegarán un comportamiento inmoral o escandaloso por parte del cónyuge, que a veces resulta brutal: "obligarle a usar del matrimonio delante de una hermana suya doncella y de un hijo suyo de nueve años por efectos todo de su licenciosa conducta" (39). La infidelidad conyugal se refleja en 41 denuncias, aludiéndose normalmente al trato con prostitutas ("se ha entregado con el mayor desenfreno a los vicios adulterando con cuantas mujeres libres y obscenas presenta este país y requiriendo dentro de su casa a las criadas que le han servido") (40) y en menor medida a la existencia de una relación ilícita estable, aunque en alguna ocasión incluso el divorcio se solicita al descubrirse que el marido es bígamo. No es raro que la esposa padezca enfermedades venéreas como consecuencia de las veleidades sexuales de su cónyuge: María Diaz, por ejemplo, contrajo la sífilis de resultas de estas infidelidades (41).

Pero de nuevo hay que explicar estos comportamientos atendiendo a las condiciones en las que se desenvolvía la existencia cotidiana de estos individuos: dado el grado de hacinamiento propio de las viviendas populares (42), buena

(35) Ya hemos puesto de relieve esta agresividad latente en MORGADO GARCIA, A., Derecho de asilo y delincuencia en la diócesis de Cádiz, Cádiz, 1991.

(36) Vid. FARGE, A., Vivre dans la rue à Paris au XVIIJe siécle, París, Gallimard, 1992.

(37) 529, Margarita de los Reyes (1749).

(38) 680, Juana de Ulloa (1714).

(39) 271, Francisca Robles (1789).

(40) 185, María Ximenez (1789).

(41) 568, Maria Diaz (1772).

(42) En los barrios humildes de la ciudad nos encontramos con hasta ocho vecinos por casa (PEREZ SERRANO, J., La población de Cádiz a fines del Antiguo Régimen. Su estructura y mecanismos de renovación (1775-1800), Cádiz, 1989, p. 82). 
parte de la vida cotidiana se desenvolvía en el ámbito de la calle, apareciendo la taberna como el principal ámbito de sociabilidad (43). No es de extrañar por ello que la embriaguez aparezca en 23 casos, y en alguna ocasión es el factor ocasionante de los malos tratos corporales: "todo lo cual ha provenido de la embriaguez que regularmente padece...que le perturba el uso de la razón y hallándose privado de ella le ha sucedido traer a su casa a algunos amigos...igualmente privados con el vino y todos asquerosos meterse en la cama que con aseo y limpieza hizo" (44). Pedro de Torrres reconocerá cómo "a impulsos de bebidas de licores que aun siendo corta cantidad me privan de conocimiento y procedo con el delirio igual a el que me ocasiona una fiebre o calentura a esto se añade el ser dicha mi mujer fuerte de genio al que dándole toda libertad lejos de procurar con la prudencia y caridad cohonestar mis delirios me contradice y disputa...desatendiendo la obligación que tenemos de tapar las flaquezas de nuestros próximos" (45).

Los malentendendidos económicos también juegan un papel importante. El Cádiz de la Modernidad fue una ciudad de esposas abandonadas, puesto que el señuelo americano siempre pesó de una forma decisiva en unos hombres deseosos de resolver sus penurias económicas por medio de la emigración a las Indias (más de dos mil personas partieron de la urbe con destino a América en los años cincuenta de la centuria) (46), aunque en muchos casos esta ilusión sería un mero espejismo. El impacto social de esta emigración no hay que menospreciarlo: en el Archivo Diocesano gaditano, por ejemplo, se encuentran numerosas requisitorias formuladas por mujeres deseosas de que sus esposos vuelvan del continente americano a las cuales han dejado en la más absoluta indigencia (47). Y ello no podía dejar de reflejarse en nuestra documentación: en 32 casos se invoca una larga ausencia del hogar, como consecuencia, normalmente, de un viaje a las Indias, que a veces se prolonga durante muchos años sin que los esposos presten auxilio material a la familia abandonada y que obligará a la mujer a trabajar para subvenir las necesidades del hogar, normalmente como criada o lavandera, si bien en alguna ocasión se supera lo peor gracias a la caridad de los vecinos (48) o de las autoridades eclesiásticas (49). Pero no hacía falta ir tan lejos para provocar este desamparo vital de la mujer: en otros 50 casos se expone cómo el esposo no mantiene al cónyuge, lo que provoca idénticas consecuencias, apareciendo en algunas ocasiones una negativa pura y simple a ejercer un trabajo estable y productivo: algunos maridos pasan todo el tiempo en tabernas y garitos de juego, lle-

(43) Constatado por FARGE, A., Vivre. Algunas observaciones para el caso gaditano en MORGADO GARCIA, A., Derecho de asilo y delincuencia en la diócesis de Cádiz, Cádiz, 1991, pp. 144-145. Estos establecimientos proliferaron enormemente en el Cádiz dieciochesco: según el padrón de 1801 había 577 taberneros (PEREZ SERRANO, J., Cádiz, p. 171).

(44) 154, Bernada Jacinta de Salvatierra (1715).

(45) 628, Antonia Vicenta Alvarez (1787).

(46) GRUPO INDIANO, "Cádiz: plataforma de emigración a Indias 1750-1760", Trocadero, 4, 1992 , p. 91.

(47) Vid. PASCUA SANCHEZ, M.J. de la, "La cara oculta del sueño indiano: mujeres abandonadas en el Cádiz de la Carrera de Indias", Chronica Nova, 21, 1993- 1994, pp. 441-468.

(48) 271, Francisca Gutierrez (1785).

(49) 680, Catalina Jurado (1717). 
gando a obligar a la esposa a trabajar como lavandera (50), ama de leche, criada (51) o incluso como prostituta (52). En 1801 la cuarta parte de las mujeres gaditanas en edad activa estaban empleadas (53). ¿Hasta qué punto muchas de ellas no eran esposas abandonadas?

Otras causas tienen menos importancia. La dilapidación de los bienes dotales por parte del marido solamente aparece en 16 ocasiones (54), y las quejas vienen derivadas sobre todo por el hecho de que éste gasta los bienes de la dote al carecer de un trabajo estable: "algunas alhajas que le habian quedado de su dote fue tal la disolución del dicho que peretendía que mi parte le ministrase para jugar y gastar en vino con los demás presos" (55). Tampoco se observan muchas referencias a los malos tratos perpetrados contra los hijos, y, de hecho, en muy escasas ocasiones se alude a ellos. Estas tropelías son de muy variado tenor: castigos corporales (el hijo de Isabel Fernández llegó a morir como consecuencia de las palizas del padre) (56), insultos (el esposo de María Benavides liamaba a sus hijas rameras, puercas, arrastradas, indignas y alcahuetas) (57), el no proporcionarles una educación ("teniendo el mayor catorce años no ha sido posible el conseguir lo destine a algún ministerio u oficio") (58), la negativa a instruirles en la doctrina cristiana ("queriendo la madre documentarlos cristianamente el padre se oponía") (59)...

No parecen jugar tampoco un papel demasiado importante en la desintegración de la vida conyugal los malentendidos de carácter sexual: solamente en dos casos se hace alusión a la homosexualidad del varón (60) y en diez a su impotencia. Pero los pleitos derivados de esta última resultan sumamente interesantes desde el punto de vista cualitativo al reflejarnos las teorías existentes en la época sobre la procreación (61) o la conformación de los órganos genitales, y, por qué no decirlo, los dramas individuales que esta cuestión provocaba en una sociedad en la cual el fin indiscutible del matrimonio era la procreación. Oigamos nuevamente a los protagonistas: Francisca Josepha Martinez declara cómo "ha estado con el susodicho todas las noches en la cama y frecuentaba el solicitar tener actos carnales y aunque ha tenido alteración ha sido poca sin que jamás haya penetrado el vaso aunque a la puerta del sí ha seminado siempre que ha tenido dicho

(50) 643, Paula María Gandulfo (1739).

(51) 568, María Albendi (1778).

(52) 683, Juana de la Vega (1759); 1163, Antonia Josef González (1797).

(53) PEREZ SERRANO, J., Cádiz, p. 153.

(54) Casey nos recuerda cómo es la esposa, y no el marido, quien tiene el derecho de libre disposición de los bienes dotales (CASEY, J., "La familia en la Andalucía del Antiguo Régimen", Historia 16, 57, 1981).

(55) 154, Bernarda Jacinta de Salvatierra (1715).

(56) 805, Isabel Fernández (1789).

(57) 1163, María Benavides (1796).

(58) 628, Francisca Delgado (1787).

(59) 704, María Josefa Ponce (1793).

(60) "Ha admitido a su obsequio a Don Ginés de Segovia...dando con este trato el mayor escándalo" (1163, Josefa González, 1795).

(61) Vid. SANTILLANA PEREZ, M., La vida: nacimiento, matrimonio y muerte en el partido de Cäceres en el siglo XVIII, Gáceres, 1992. 
acto pero jamás la ha llegado a romper aunque ha tenido muchos y repetidos actos" (62). María Seco, por su parte, expresa que su marido "es eunuco a quien enteramente faltan todas las partes y miembros necesarios para la generación" (63).

Quizás el caso más interesante al respecto sea el de Luisa Teresa de Alanis, que planteaba pleito de divorcio en 1717 , por cuanto en el mismo aparece reflejado prolijamente el complejo proceso de averiguaciones empleado por los tribunales para dilucidar esta cuestión (64). Tras alegar los infructuosos intentos de: su esposo por consumar el matrimonio, el reconocimiento médico señaló que "ha registrado al dicho sus partes genitales miembro viril y le ha hallado muy perfecto en buena proporción ni muy grande ni muy pequeños los genitales lo mismo correspondiente al miembro...de no poder conseguir su cumplimiento del acto puede ser enfermedad que son haberse obstruido aquellas vías por donde pasan espíritus flatulentos para el cumplimiento del acto y ésa es enfermedad curable para que se restituya a su actual estado por los pocos años que tiene y le parece que es capaz para poder tener actos con doncella viuda o otra mujer". A su vez, la demandante fue reconocida por la correspondiente matrona, la cual declaraba "que no está doncella que está curada sin embargo de estar comprimida aquella parte por algún daño que se pudo haber dado de aguas que suelen usar algunas para parecer doncellas". Un tribunal médico resolvía finalmente "ser cierta la impotencia del dicho pues por la inspección de las partes verendas y constar que en el uso del matrimonio no ha podido consumar la operación pues no ha desflorado: el claustro virginal ni sentido aquella sensible delectación que en la eyaculación de la genitura se experimenta en dichos actos", definiendo así la impotencia como perpetua.

A fin de clarificar de una vez por todas esta situación, la abuela de la denunciante (65) fue requerida por el obispo a que durante tres noches seguidas observara si se consumaba el matrimonio, y la narración de lo sucedido nos muestra la amplitud de este pequeño gran drama cotidiano. A la primera noche, el marido le respondió que "aunque estuviese cincuenta años con ella sería lo mismo". A la segunda le propuso el ingreso en un convento (a lo que María Teresa se negó), irse él a las Indias a condición que ella no divulgara su impotencia ("que haga lo que quiera"), o "que se dejase abrir con una vela o con una moneda de oro que eran instrumentos con que se abrían las doncellas" "que no consentía en tal cosa que no: era la ley de Dios"). Durante la tercera noche, finalmente, tras untarse el marido el miembro viril con aceite, "solicitó tener acto carnal con la dicha su mujer y aun entró la cabeza (la abuela de la demandante) en el cuarto y los vio en la forma que lo pudieran tener y le oyó decir a la dicha...quita pícaro no ves que no entra luego puedes ir con embustes al señor obispo" (66).

Pero la tragedia tiene otras perspectivas. En algunas ocasiones, ciertamente también excepcionales, nos encontramos con casos de matrimonios completa-

(62) 337; Francisca Josefa Martinez (1713).

(63) 704, Maria Seco (1730).

(64) Reflejado para el caso'francés en DARMON, P., op. cit.

(65) También en Francia.se ha constatado la irrupción en la intimidad del acto conyugal de testigos comisionados para determinar la impotencia dle varón. Vid. DARMON, P., op. cit.

(66) 185, María Teresa de Alanis (1717). 
mente forzados (67): Josefa María de Medina fue obligada a contraer matrimonio con un sujeto de su total repugnancia, por lo que se negó en redondo a la cohabitación con su marido, ante lo cual su madre y los familiares del novio "me desnudaron e introdujeron en una cama con el dicho y sin embargo de las solicitudes y diligencias de éste para consumarlo puse tal resistencia que no pudo conseguirlo por el tiempo de tres días y tres noches en que por todas partes se repitieron las diligencias antes para ello hechas hasta que en la cuarta vencida de las fuerzas y amenazas del dicho y no leves golpes que las acompañaron y conociendo me estaba embarazada de la fuga...por haber puesto mis padres en la puerta de el dormitorio sus camas gozó mi virginidad" (68).

Un nuevo drama que merece que dejemos hablar a su protagonista: Francisca Serrano nos cuenta cómo "por el año pasado de 1705 siendo yo de edad de once años mi madre Doña Antonia Murillo a cuyo cuidado estaba por haber muchos años que se hallaba en los reinos de Indias D. Juan Serrano mi padre me propuso casamiento con $\mathrm{D}$. Pedro de Soto Calderón a quien yo tenía capital odio y aborrecimiento y viendo mi resistencia a consentir en ello después de haber experimentado inútiles cuantas persuasiones y ofrecimientos discurrió su viveza y deseo de que se efectuase se valió de la amenaza de entrarme religiosa en uno de los conventos de la ciudad de Jerez proponiéndome le quedaba sólo este recurso para mi manuntención en la cortedad de medios con que nos hallábamos por la ausencia de mi padre de suerte que me hicieron preciso haber el casarme o el vivir para siempre reclusa en un monasterio profesando vida religiosa sin vocación a ella y no sólo apartada de la comunicación de mi madre que era el único objeto de mi estimación y cariño en lo corto de mi edad si también imposibilitada o dificultosísima su vista por la ausencia de Cádiz...habiendo procurado por todos los medios posibles evitar ambos males no pude conseguirlo por lo que padecí el primero que me casasen con dicho $\mathrm{D}$. Pedro con tan grande repugnancia como mostraron todas las señales exteriores que en mí se reconocieron el día de la celebración de la boda en cuya resistencia continué todo el tiempo que viví en su compañía no condescendiendo a los actos conyugales sino en rara vez y forzada de las persuasiones de dicha mi madre y riñas de mi marido sin embargo de ellas aparté cama y aunque quise diferentes veces suscitar judicialmente la nulidad de matrimonio no lo hice así porque no habiéndoseme permitido consulta sobre ello no tenía tan exacta noticia como ahora de mi clara justicia porque siempre me lo embarazó mi madre recelando la nota que causaría en esta ciudad" (69).

Pero estos casos son claramente excepcionales, y todo parece indicar que las preocupaciones de las mujeres gaditanas eran muy inmediatas: lo que ante todo desean es un trato justo por parte de sus maridos, que los mismos no abusen de

(67) En cualquier caso, los estudios sobre la familia del Antiguo Régimen han probado sobradamente cómo, al menos en las clases altas, el factor menos determinante para la contracción de matrimonio era la voluntad de los cónyuges. Vid. MACFARLANE, A., Marriage and love in England. Modes of reproduction 1300-1840, Londres, 1986; SHORTER, E., The making of the modern family, Nueva York, 1977; o STONE, L., The family, sex and marriage in England 1500-1800, Londres, 1979. Para el caso extremeño, vid. TESTON NUÑEZ, I., op. cit.

(68) 707 , Josefa Maria de Medina (1700).

(69) 337, Francisca Serrano, (1717). 
su autoridad por medio de los castigos físicos y las injurias verbales, que les guarden fidelidad, coadyuven a las necesidades materiales del hogar y muestren un comportamiento decente.

\section{LAS QUEJAS DE LOS MARIDOS}

En el caso de los esposos, su principal aspiración radica en que su esposa sea sumisa, obediente y honesta, de ahí que las referencias al violento carácter de sus cónyuges suelan aparecer (concretamente, en catorce ocasiones) como causa de petición de divorcio: "le he tolerado algunas sinrazones dimanadas de la improporción de su genio y de haberle prevenido se abstuviese en todo a moderarse" (70), "empecé a experimentar en la susodicha un genio poco sociable, áspero y nada afecto a el cuidado de las cosas domésticas, aseo de mi persona y custodia de su casa" (71), "no querer sujetarse a una regular cristiana decente vida refrenando lo intrépido y altivo de su genio" (72). Al igual que sus esposas, los maridos también manifiestan haber cumplido con sus obligaciones para recalcar lo reprochable de estos comportamientos: "haber vivido maridablemente con la dicha mi mujer alimentándola y vistiéndola de todo lo necesario tratándola con la estimación y cariño conveniente para conservarnos en paz y unión" (73), "cumpliendo por su parte con la obligación del estado estimándola asistiéndola y cuidándola en el sustento y vestuario" (74), "procurando asistirla y mantenerla con la decencia correspondiente" (75).

Los factores de carácter moral también juegan un cierto papel, aludiéndose a un comportamiento disoluto (ocho casos): "se ostenta con las palabras más obscenas y trajes y como si fuera una prostituta, se excusa de su aseo personal, ultraja a los vecinos" (76), "abriga en la casa donde habita a un hombre soez de infima esfera llamado Antonio Piache hombre vago y conocido en esta ciudad por entregado a todo genero de vicios con quien está de continuo de dia y noche escandalizando a cuantas personas lo notan y advierten" (77)...o a la infidelidad (catorce).

Otros motivos, por el contrario, son menos invocados: en cinco ocasiones se expone cómo la esposa se ha ausentado del hogar, en cuatro su negativa a cumplir con el débito conyugal, en dos a su carácter derrochador ("gastar por si mi mujer los arrendamientos que recibe como casera de los vecinos, tal vez para mantener o aliviar a dicha su hermana, abuela, madre y dos hermanos, cuyo dispendio me acarrean atrasos considerables y total ruina") (78), en cuatro a las calumnias e injurias recibidas de ella (79) y en ocasiones muy aisladas se alude a

(70) 676, Pedro de la Rue (1737)

(71) 626, Francisco Volta (1754).

(72) 683, María Valcárcel (1759).

(73) 346, Juan Francisco de Cruz (1701).

(74) 633, Pedro Ulloa (1711).

(75) 271, Josef Morales (1785).

(76) 805, Manuel García (1789).

(77) 271, Ignacio Rodríguez de Lorenzana (1783).

(78) 271, Pedro López de Mariana (1785).

(79) 271, Josef Morales (1785), 271, Pedro López de Mariana (1785). 
las discordias mantenidas con la suegra (80), los celos de la esposa, el intento de ésta de administrar los bienes del marido haciéndole pasar por demente (81), su nula aplicacion a las funciones domesticas (82), su distinta religión (83) o su impotencia ("se halla imposibilitada de la consumación del matrimomio a causa de la demasiada union de lo músculos y ligamentos que coligan de cuello de la matriz la que está expuesta a una grande hemorragia de sangre violentándola a dicho uso lo que cree y juzga que pasados ocho o diez años podrá tenerlo mas siempre con peligro proximo") (84), arguyéndose en alguna ocasión el mal ejemplo que se da a los hijos.

\section{UN FINAL CASI NUNCA FELIZ}

Todas las demandas de divorcio eran dirigidas al Provisor y Vicario General, cuyo tribunal radicaba en la Audiencia episcopal gaditana, el cual ordenaba que la parte denunciante proporcionara toda la información necesaria y daba comisión al Notario Mayor para que interrogase a una serie de testigos que dieran fe de las motivaciones expuestas. Posteriormente venía el intercambio de oficios proporcionados por los procuradores de ambas partes, hasta que finalmente el Provisor y Vicario General dictaba la sentencia final, si bien la misma podía ser apelada al Metropolitano de Sevilla, al Nuncio Apostólico en España, y, finalmente, al Tribunal de la Rota, lo que motivaba que los pleitos se prolongaran en alguna ocasión durante muchos años, aunque la mayoría acabaron siendo sobreseídos.

Las sentencias son muy variadas: en 23 ocasiones se decretó el depósito de la mujer en casa de sus amigos o familiares a fin de librarla del acoso del marido o en la Casa de Recogidas de san Pablo (85) por su comportamiento disoluto (el encierro resulta así la mejor forma de salvaguardar el honor de la mujer) (86), en 19 ocasiones la parte denunciante se desiste, alegando normalmente los perjuicios que se seguirían al matrimonio de mantener su actitud: "temerosos de Dios y bien desengañados de la poca razón que nos ha asistido para haber sustentado la demanda de divorcio" (87), "habiendo advertido uno y otro lo preciso que es la paz en el matrimonio" (88), "para el servicio de Dios y tranquilidad de nuestras conciencias" (89), "a consecuencia de reflexionar cuánto contribuye a la salvación de nuestras almas, el recíproco perdón y a la tranquilidad de ésta y perfecta vida espiritual la unión que nos preceptúa y a que nos instiga la religión y naturaleza del sacramento" (90). A veces el mismo se produce tras un acuerdo previo entre los esposos que tiene

(80) 701, Josef Ramírez (1790).

(81) 802 , Diego de Medina (1755)

(82) 690 , Jacinto Cabero (1783).

(83) Matías Gutierrez manifestaba cómo su mujer seguía conservando la relighión hebraica (743, Matías Gutierrez, 1777).

(84) 568, Agustín Pejenas (1778).

(85) Esta institución fue fundada a fines del siglo XVII para acoger a las prostitutas arrepentidas.

(86) Vid. SANCHEZ LORA, J.L., Mujeres, conventos $y$ formas de la religiosidad barroca, Madrid, Fundación Universitaria Española, 1988.

(87) 633, María Teresa de Bonora (1709).

(88) 683, Magdalena Teresa (1759).

(89) 683, María Moreno (1759).

(90) 627, Isabel Ximénez Delgado (1773). 
como finalidad eliminar de raíz las causas que originaron el litigio: Juan Fernández Santiago y Domingo Baccala prometieron no volver a maltratar a sus esposas (91), Josepha Burriales se comprometió a dejar a su amante y mudarse con sus hijos a Rota proporcionándole su marido 10 pesos mensuales (92), Juan Rodríguez a abandonar el alcohol, no tener trato ilícito y tratar con dulzura a su esposa (93), Manuela Estévez a no mezclarse "en las cosas que son de su dependencia ni tampoco en que salga o entre tenga tratos y contratos con cualesquiera clase de gentes en los términos lícitos y permitidos" (94).

Solamente en once casos las autoridades eclesiásticas concedieron el divorcio (95), ordenándose al marido que mantuviera económicamente a su esposa (Joseph Rodriguez tuvo que pagar 12 pesos al mes (96), en tanto que en otros cinco se decidió que las razones alegadas no eran suficientes. Finalmente, algunas veces las autoridades eclesiásticas pretenden resolver la situación por medio de la corrección de los abusos más notorios (la jerarquía no solamente vigilaba o castigaba, también corregía los comportamientos) al ordenarse a las partes hagan vida maridable, que la esposa guarde un comportamiento honesto (97), que el marido se abstenga de tratos ilícitos (98), que la mujer "hable bien y trate con amor a su marido" (99), o que ésta se comporte "con la subordinación y afecto marital que le debe" (100).

Si reacias eran las autoridades eclesiásticas a conceder el divorcio, más aún lo eran a decretar la nulidad del matrimonio, lo que tuvo lugar solamente en tres casos, fechados todos ellos en la primera mitad de la centuria, debidos a bigamia (101), haber tenido el marido trato carnal con su suegra antes del matrimonio (102) o impotencia (a Pedro de la Rosa, tras el pertinente reconocimiento médico, se le descubrió "estar imposibilitada a causa de una parálisis del concubito o junta conyugal para la generación ha diez y ocho años que se halla con el efecto de no poderse levantar el miembro viril por el cual está absolutamente inhábil al estado del matrimonio") (103).

Las autoridades eclesiásticas, pues, defraudaron casi siempre las expectativas y las esperanzas que en ellas habían depositado estos cónyuges infelices. Es probable que, en el fondo, muchos de ellos no desearan realmente la separación, especialmente las mujeres, las más perjudicadas desde el punto de vista económico si el divorcio era consumado, y que solamente pretendieran que el cónyuge causante del agravio fuese expuesto públicamente a la reprobación. Por supuesto, la felicidad de los afectados se verá supeditada a la salvaguardia de la institución.

(91) 185, María Andrea Ximénez (1714) y 731, Isabel Cueto (1767).

(92) 625, Juan Marchante (1775).

(93) 1163, Ana María Martinez (1799).

(94) 805, Manuela Estevez (1773).

(95) Esta renuencia por parte de las autoridades eclesiásticas también ha sido puesta de relieve por García Cárcel para el caso barcelonés (Historia...).

(96) 684, Joseph Rodríguez (1733).

(97) 742, Manuel de Báez (1768).

(98) 267, Martín Alvarez (1769).

(99) 690, Jacinto Cabero (1783).

(100) 743, María Ximénez (1783).

(101) 669, Eulalia Subirán (1732).

(102) 643, Francisca García (1739).

(103) 643, María Moreno (1740). 